\title{
Multicylinder Engine Shaking Forces and Moments
}

\author{
Samuel Doughty ${ }^{1}$
}

\begin{abstract}
The dynamic forces and moments arising from the motion of internal components in IC engines are known as Shaking Forces and Shaking Moments. These forces and moments are transmitted directly to the supporting structure, whether it be a concrete block or a ship's frame. They can cause significant damage if not properly evaluated at the design stage. It should be noted that these are inertial reactions only, and are unaffected by cylinder firing pressure. By a direct appeal to fundamental momentum principles, this paper presents an elegant and completely general approach to their determination, based on first principles. This is much simpler than the conventional direct approach through the piece-bypiece application of Newton's Second Law.
\end{abstract}

Keywords — momentum principles, kinematic functions, shaking forces, shaking moments.

Abstrak-Gaya dinamis dan momen timbul dari gerakan komponen internal dalam mesin IC dikenal sebagai Gaya Getaran dan Momen Getaran. Gaya dan momen ini ditransmisikan langsung ke struktur pendukung, apakah itu sebuah blok beton atau bingkai kapal. Hal ini dapat menyebabkan kerusakan yang signifikan jika tidak dievaluasi pada tahap desain. Perlu diketahui bahwa ini adalah reaksi inersia saja, dan tidak terpengaruh oleh tekanan tembak silinder. Dengan daya tarik langsung ke prinsip momentum fundamental, makalah ini menyajikan sebuah pendekatan yang elegan dan benar-benar umum untuk determinasi mereka, berdasarkan prinsip-prinsip pertama. Ini jauh lebih sederhana dibandingkan dengan pendekatan konvensional langsung melalui aplikasi sepotong demi sepotong Hukum Kedua Newton.

Kata Kunci— prinsip momentum, fungsi kinematik, gaya getaran, momen getaran.

\section{INTRODUCTION}

$\mathrm{I}_{\mathrm{n}}^{\mathrm{n}}$ ternal combustion engines (and other slider crank machines, such as reciprocating compressors) are widely used in all parts of modern industry. They are manufactured around the world, in almost every nation that has a developed industrial base. Despite this ubiquity, there are many aspects of the machine that are not well understood by those who apply them. One of those misunderstood characteristics is the loads that such an engine (or compressor) can impose upon the underlying support. These loads are technically known as Shaking Forces and Shaking Moments, and as the names imply, they are oscillatory in nature, tending to shake the supporting structure. If the machine is supported on a concrete block foundation, these are the loads that will tend to shake that foundation block, laterally, vertically, and in a rocking motion. If the machine is in a ship, these loads are transmitted into the structure of the ship, shaking the entire ship. The impact of a reciprocating machine on the supports can be severe, and can result in damage elsewhere, making it necessary that the source of these loads be fully appreciated.

When any sort of force analysis is required, it is common engineering practice to apply Newton's Second Law to each part of the moving mechanism, and thus attempt to follow the transfer of forces through the entire system. This approach has been employed by Guntur and Yulia [1] and by Zubaydi, et al. [2]. Indeed, this is the necessary way to proceed when the internal forces are to be determined, as demonstrated by Doughty [3].

However, for the problem at hand, the determination of the net external reactions alone, there is a much more simple and powerful approach available, based on very

${ }^{1}$ Samuel Doughty is Principal Analyst, Machinery Dynamics Research, Dubuque, Iowa, USA 52003. sdoughtyll@gmail.com. fundamental momentum principles, as shown by Doughty [4].

It is important to understand that the shaking forces and moments are net reactions. Thus they represent the vector sum of all attachment forces and associated moments, but not necessarily the force or moment at any single attachment point. Thus, for example, if an engine is supported vertically at three points, then the vertical shaking force is the sum of the vertical forces at all three supports. These values provide design targets for the design of the support structure.

The analysis to follow consists of three parts:

1. A statement of the fundamental momentum principles underlying this development;

2. The application of those momentum principles to a multi-cylinder slider-crank machine.

3. A brief sketch of the kinematic analysis required to implement the results previously obtained. A much more detailed kinematic analysis is presented in the Appendix - Cylinder Kinematics.

Following the analysis, example calculations are presented, with numerical results.

\section{ANALYSIS}

The usual approach to the determination of shaking forces and moments in a slider-crank mechanism is by means of a detailed analysis of the internal forces, leading eventually to the bearing forces and the external reactions. The present analysis will bypass all of those internal details by appeal to general momentum principals that move directly to the external reactions.

\section{A. Fundamental Principle}

The basis for this solution is the two momentum principles as stated by Crandall, et al. [5]:

- The resultant external force acting on a system of particles is equal to the time rate of change of the 
system's linear momentum with respect to an inertial frame.

- For a system of particles, the total moment with respect to a fixed point is equal to the time rate of change of the system total angular momentum, referred to that same fixed point.

It matters not at all whether the particles are each entirely unconstrained (as in a gas) or if there are a vast number of internal constraints acting between the particles (as in a rigid body). In the case at hand, there are countless constraints acting at the molecular level to maintain interatomic spacing in the rigid bodies that comprise the slider-crank mechanism, but these constraint forces have no bearing on the momentum principles stated above.

\section{B. Coordinate Systems}

A single engine cylinder is first considered, as shown in Figure 1. The cylinder is inclined to the vertical by the angle $B_{j}$ and the crank angle, $\theta$, is measured from the cylinder center line. The global coordinate system $O-$ $X Y$ is upright, while the local cylinder coordinate system, $O-x y$ is inclined to align with the cylinder. Unit vectors $\mathbf{i}, \mathbf{j}$, and $\mathbf{k}$ are aligned with the global coordinate system.

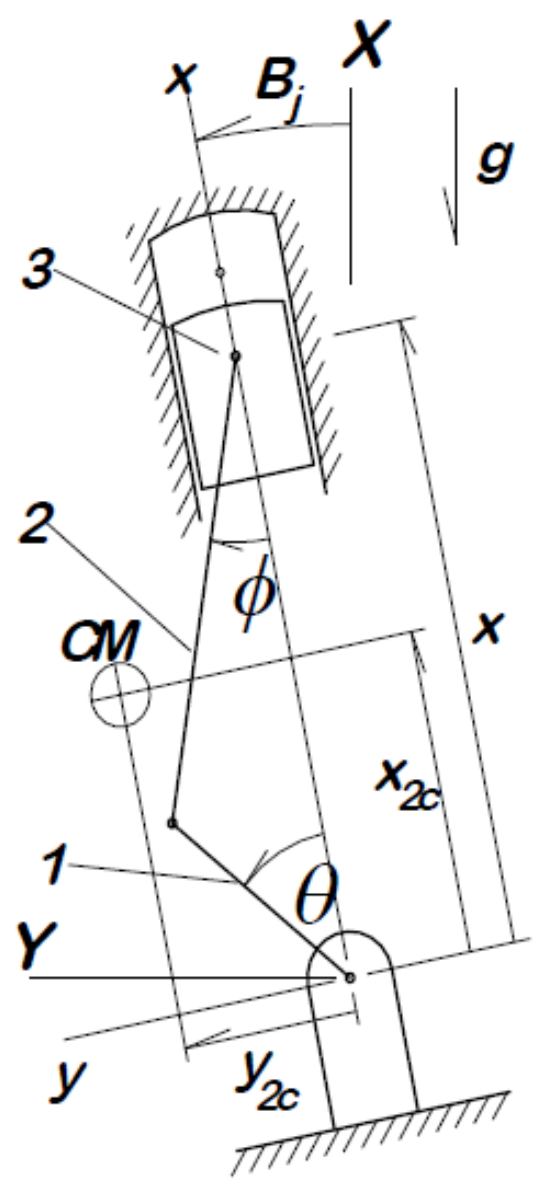

Figure 1. Slider-Crank Mechanism for a Single Engine Cylinder

There are three bodies involved in a single slider- crank mechanism: (1) the crank, (2) the connecting rod, and (3) the piston. Body coordinate systems, denoted $U_{i}-V_{i}$, are attached to each of these bodies as shown in Figure 2. These are used in order to specify the position of the body center of mass clearly. Thus, for example, on the connecting rod, the body center of mass is located by body coordinates $\left(u_{2 c}, v_{2 c}\right)$ in the $U_{2}-V_{2}$ body coordinate system, where the 2 in the subscript refers to the connecting rod. This same center of mass has coordinates $\left(x_{2 c}, y_{2 c}\right)$ in the cylinder coordinates, and coordinates $\left(X_{2 c}, Y_{2 c}\right)$ in the global coordinate system.

Each slider-crank mechanism executes only planar motion in a plane at position $Z_{j}$ along the crankshaft axis. For a single cylinder engine or a $\mathrm{V}$-twin, $Z_{j}$ is commonly taken as zero, but for an engine with many cylinders, there is a different value of $Z$ for each cylinder or pair of cylinders, depending on the details of the crankshaft and block layouts.

\section{Momentum Expressions}

The position of the $i^{\text {th }}$ body center of mass in the $j^{\text {th }}$ slider-crank is given in vector form as

$$
\mathbf{r}_{i j}=\mathbf{i} X_{i c}+\mathbf{j} Y_{i c}+\mathbf{k} Z_{j} \quad i=1,2,3
$$

The global position, re-expressed in terms of the local cylinder coordinates, is

$$
\begin{aligned}
\mathbf{r}_{i j}= & \mathbf{i}\left[x_{i c}\left(\theta_{j}\right) \cdot \cos B_{j}-y_{i c}\left(\theta_{j}\right) \cdot \sin B_{j}\right] \\
& +\mathbf{j}\left[x_{i c}\left(\theta_{j}\right) \cdot \sin B_{j}+y_{i c}\left(\theta_{j}\right) \cdot \cos B_{j}\right] \\
& +\mathbf{k} Z_{j}
\end{aligned}
$$

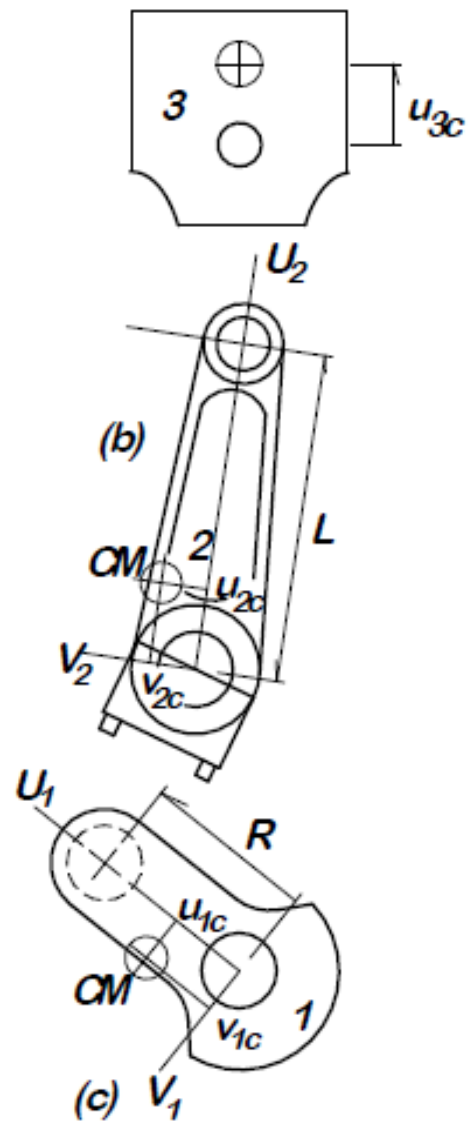

Figure 2. Individual Component Parts of the Slider-Crank Mechanism

where $\mathrm{i}=1,2,3$. The velocity of this same center of mass is found by time differentiation. In taking this derivative, the well known concept of velocity coefficients (see for example Doughty [6] or Paul [7]) are employed to express the component velocity in terms of the crank speed, $\dot{\theta}_{J}$.

$$
\begin{aligned}
\mathbf{V}_{i j}= & \mathbf{i} \dot{\theta}\left[\cos B_{j} \cdot K_{x i c}\left(\theta_{j}\right)-\sin B_{j} \cdot K_{y i c}\left(\theta_{j}\right)\right] \\
& +\mathbf{j} \dot{\theta}\left[\sin B_{j} \cdot K_{x i c}\left(\theta_{j}\right)+\cos B_{j} \cdot K_{y i c}\left(\theta_{j}\right)\right]
\end{aligned}
$$


where, $K_{x i c}(\theta)$ and $K_{y i c}(\theta)$ are called velocity coefficient functions. The use of velocity coefficients is described further below in the section titled Kinematics. The derivation of all necessary velocity coefficients (and velocity coefficient derivatives) is provided in the Appendix - Cylinder Kinematics. The subscript on $\dot{\theta}$ is dropped because the crank shaft is a single rigid body, and all the crank throw angular velocities have the same angular velocity, $\dot{\theta}$.

\section{1) Linear Momentum}

For any rigid body, the linear momentum is simply the product of the mass with the center of mass velocity. Linear momenta are directly additive, so the total system linear momentum is obtained by summation over all the moving bodies. First, for the $i^{t h}$ body in the $j^{\text {th }}$ slider-crank, the linear momentum is $\mathbf{P}_{i j}$

$$
\begin{aligned}
\mathbf{P}_{i j}= & \mathbf{i} \dot{\theta} m_{i}\left[\cos B_{j} \cdot K_{x i c}\left(\theta_{j}\right)-\sin B_{j} \cdot K_{y i c}\left(\theta_{j}\right)\right] \\
& +\mathbf{j} \dot{\theta} m_{i}\left[\sin B_{j} \cdot K_{x i c}\left(\theta_{j}\right)+\cos B_{j} \cdot K_{y i c}\left(\theta_{j}\right)\right]
\end{aligned}
$$

and the total system linear momentum is then

$$
\begin{aligned}
\mathbf{P}= & \sum_{j} \sum_{i=1,2,3} \mathbf{P}_{i j} \\
= & \mathbf{i} \dot{\theta} \sum_{j} \sum_{i=1,2,3} m_{i}\left[\cos B_{j} \cdot K_{x i c}\left(\theta_{j}\right)-\sin B_{j} \cdot K_{y i c}\left(\theta_{j}\right)\right] \\
& +\mathbf{j} \dot{\theta} \sum_{j} \sum_{i=1,2,3} m_{i}\left[\sin B_{j} \cdot K_{x i c}\left(\theta_{j}\right)+\cos B_{j} \cdot K_{y i c}\left(\theta_{j}\right)\right]
\end{aligned}
$$

This result makes it clear that the system linear momentum is proportional to the crank speed and depends upon a summation over the position of the individual crank throws, $\theta_{j}$.

Based on the first of the momentum principles stated above, the external reaction forces are now determined by differentiation. Only steady operating speeds are considered, so that $\dot{\theta}=\Omega=$ constant. The net reaction forces in the global $X$ and $Y$ directions are

$$
\begin{aligned}
& R_{X}=\Omega^{2} \sum_{j} \sum_{i=1,2,3} m_{i}\left[\cos B_{j} \cdot L_{x i c}\left(\theta_{j}\right)-\sin B_{j} \cdot L_{y i c}\left(\theta_{j}\right)\right] \\
& R_{Y}=\Omega^{2} \sum_{j} \sum_{i=1,2,3} m_{i}\left[\sin B_{j} \cdot L_{x i c}\left(\theta_{j}\right)+\cos B_{j} \cdot L_{y i c}\left(\theta_{j}\right)\right]
\end{aligned}
$$

where the L's are velocity coefficient derivative functions (see the Appendix-Cylinder Kinematics for their evaluation). It is evident that the summations only need to be performed once, to calculate $R_{X} / \Omega^{2}$ and $R_{Y} / \Omega^{2}$, and these results can then be readily scaled to give the values appropriate to any operating speed.

\section{2) Angular Momentum}

In order to calculate the angular momentum of the $i^{\text {th }}$ body in the $j^{\text {th }}$ slider-crank assembly, return to the expressions given above for $\mathbf{r}_{i j}$ and $\mathbf{V}_{i j}$, equations (2) and (3). The angular momentum for this body, with respect to the origin of coordinates, is $\mathbf{H}_{o-i j}$

$$
\mathbf{H}_{o-i j}=\mathbf{r}_{i j} \times m_{i} \mathbf{V}_{i j}+I_{i c} \dot{\lambda}_{i} \mathbf{k}
$$

where

$I_{i c}=$ mass moment of inertia with respect to the center of mass

$\dot{\lambda}_{i}=$ body rotation rate, positive in the sense of crank rotation, $\theta$.

For body 1 , the crank, the $\dot{\lambda}$ represents crank speed, $\dot{\theta}$, or for body 2 , the connecting rod, it is the obliquity angle rate, $-\dot{\phi}$. For the pistons $\dot{\lambda}_{3}=0$ since the pistons do not rotate. Only the $\mathbf{i}$ and $\mathbf{j}$ components of this cross product are of interest. The $\mathbf{k}$ component is not considered because it is subject to the load torque on the engine, the gas pressure torques from the firing cylinders, etc. For the two components of interest here, the cross product results are:

$$
\begin{aligned}
& H_{O X}=-\dot{\theta} \sum_{j} \sum_{i=1,2,3} m_{i} Z_{j}\left[\sin B_{j} \cdot K_{x i c}\left(\theta_{j}\right)+\cos B_{j} \cdot K_{y i c}\left(\theta_{j}\right)\right](9) \\
& H_{O Y}=\dot{\theta} \sum_{j} \sum_{i=1,2,3} m_{i} Z_{j}\left[\cos B_{j} \cdot K_{x i c}\left(\theta_{j}\right)-\sin B_{j} \cdot K_{y i c}\left(\theta_{j}\right)\right](10)
\end{aligned}
$$

Again, holding crank speed constant, the time derivative of these two angular momentum components give the shaking moments in the global $X$ and $Y$ axes, respectively:

$$
\begin{gathered}
M_{O X}=-\Omega^{2} \sum_{j} \sum_{i=1,2,3} m_{i} Z_{j}\left[\sin B_{j} \cdot L_{x i c}\left(\theta_{j}\right)+\cos B_{j} \cdot L_{y i c}\left(\theta_{j}\right)\right] \\
M_{O Y}=\Omega^{2} \sum_{j} \sum_{i=1,2,3} m_{i} Z_{j}\left[\cos B_{j} \cdot L_{x i c}\left(\theta_{j}\right)-\sin B_{j} \cdot L_{y i c}\left(\theta_{j}\right)\right]
\end{gathered}
$$

It should be noted at this point that the mass moments of inertia for both the crank and the connecting rod do not figure into these calculations. This is significant, because they are necessary parameters for the correct application of Newton's Second Law. Further, the cylinder pressure is not involved, although this too is required for the correct application of Newton's Second Law. This is an important benefit, unique to this approach.

\section{KINEMATICS}

There are two kinematic aspects that require further attention. The first is the concept of velocity coefficient and velocity coefficient derivative functions, as used above to express the momenta and momentum derivatives. The second is the geometry of the multicylinder crank.

\section{A. Velocity Coefficients}

The slider-crank mechanism has only one degree of freedom, so that when the crank angle is specified, all other positions are completely determined. Consider any geometric variable in the slider-crank, denoted as $s$, where $s$ may be $\phi, x, x_{1 c}, y_{1, c}, x_{2 c}, y_{2 c}$, or $x_{3 c}$. The dependence of $s$ on the crank angle $\theta$ is indicated mathematically as

$$
s=f(\theta)
$$

The velocity of $s$ is then expressed by differentiation with respect to time

$$
\dot{s}=\dot{\theta} \frac{d f(\theta)}{d \theta}=\dot{\theta} \cdot K_{s}(\theta)
$$

The quantity designated as $K_{S}(\theta)$ is simply the indicated derivative, and because it multiplies $\dot{\theta}$ to produce $\dot{s}$, it is called a velocity coefficient, that is, a multiplier of one velocity to produce another.

\section{B. Velocity Coefficient Derivatives}

To carry this process a step further, consider a second differentiation with respect to time,

$$
\begin{aligned}
\ddot{s} & =\frac{d}{d t}\left[\dot{\theta} \cdot K_{s}(\theta)\right] \\
& =\ddot{\theta} \cdot K_{s}(\theta)+\dot{\theta}^{2} \frac{d}{d \theta}\left[K_{s}(\theta)\right] \\
& =\ddot{\theta} \cdot K_{s}(\theta)+\dot{\theta}^{2} \cdot L_{s}(\theta)
\end{aligned}
$$


The quantity $L_{S}(\theta)$ is called a velocity coefficient derivative, simply a description of its nature as the derivative of a velocity coefficient. With these functions defined, the description of velocities and accelerations for single degree of freedom systems is quite simple.

The detailed determination of the original function, $f(\theta)$ for the various variables is shown in detail in the Appendix-Cylinder Kinematics. The system of equations described there is uniquely suited to computer implementation, with the substitution of numerical values from each calculation into those that follow it. Algebraic substitution, while possible, is not enlightening and is to be avoided.

\section{Multicylinder Crank Geometry}

In the operation of a multicylinder engine, there is a relation between the individual cylinder crank angles, the cylinder bank angles, and the crank shaft angles. In order to examine this, consider Figure 3 , and note that all angles are positive in the direction of crankshaft rotation.

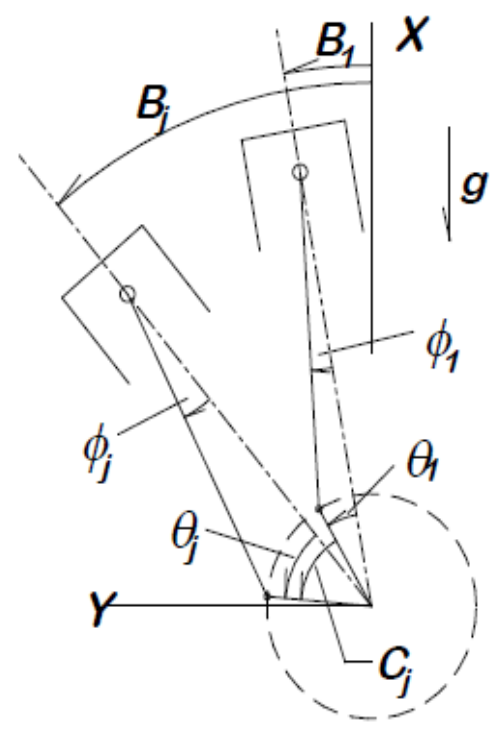

Figure 3. Angle Relations

The bank angles, $B_{1}, B_{2}, \ldots B_{j}$ describe the angular orientation of each cylinder with respect to the vertical. For an in-line engine, all the bank angles will be the same. For a V-type engine, typically there is one bank angle for the even numbered cylinders and a different angle for the odd numbered cylinders.

The crankshaft angles, $C_{j}$ describe the angular position of each crank throw with respect to a reference throw designated as \#1. In the event that the engine is a V-twin type, the sort commonly used in motorcycles, there is only a single crank throw with the connecting rods from both cylinders attached to it.

The angle that is of importance in describing what the slider-crank geometry and cylinder pressure in an individual cylinder is the crank angle, $\theta_{j}$ measured from cylinder center line to the associated crank pin. With the crankshaft considered as a rigid body, there is only one independent crank angle, designated $\theta_{1}$, and the purpose here is to relate the other crank angles to $\theta_{1}$.

Considering the geometry of Figure 3 , it is evident that the required relation is:

$$
\theta_{j}=\theta_{1}+B_{1}-B_{j}+C_{j}
$$

It is important to recognize that this is dependent both on the crankshaft geometry and the cylinder bank angles.

\section{EXAMPLE CALCULATIONS}

The process developed above is quite general and easily applied to a wide variety of engine configurations. In order to have more directly comparable results, all of the examples presented here employ the same basic cylinder parameters. These parameters are a rough approximation to the cylinders of the British Polar M40M marine engine [8]. The basic cylinder parameters are in the Table 1.

TABLE1.

\begin{tabular}{lcc}
\multicolumn{3}{c}{ BRITISH POLAR M40M MARINE ENGINE PARAMETERS } \\
\hline \hline Crank Radius & $\mathrm{R}$ & $0.285 \mathrm{~m}$ \\
\hline Connecting Rod Length & $\mathrm{L}$ & $1.400 \mathrm{~m}$ \\
\hline Single Crank Mass & $m_{1}$ & $420 \mathrm{~kg}$ \\
\hline Connecting Rod Mass & $m_{2}$ & $244 \mathrm{~kg}$ \\
\hline Piston Mass & $m_{3}$ & $720 \mathrm{~kg}$ \\
\hline Crank CM & $u_{1 c}$ & $0.020 \mathrm{~m}$ \\
\cline { 2 - 3 } & $v_{1 c}$ & $0.0 \mathrm{~m}$ \\
\hline Connecting Rod CM & $u_{2 c}$ & $0.490 \mathrm{~m}$ \\
\hline Piston CM & $v_{2 c}$ & $0.0 \mathrm{~m}$ \\
\hline & $u_{3 c}$ & $0.020 \mathrm{~m}$ \\
& $v_{3 c}$ & $0.0 \mathrm{~m}$ \\
\hline
\end{tabular}

\section{Case 1 V-Twin Engine}

The parameters for this case are in Table 2 below. Note that the two cylinders are in slightly different planes, as indicated by the different values for $Z_{1}$ and $Z_{2}$.

TABLE 2.

V-TWIN ENGINE PARAMETERS

\begin{tabular}{cccccc}
\hline \hline$B_{1}$ & $B_{2}$ & $Z_{1}$ & $Z_{2}$ & $C_{1}$ & $C_{2}$ \\
\hline $0^{\circ}$ & $45^{\circ}$ & $-0.012 \mathrm{~m}$ & $+0.012 \mathrm{~m}$ & $0^{\circ}$ & $0^{\circ}$ \\
\hline \hline
\end{tabular}

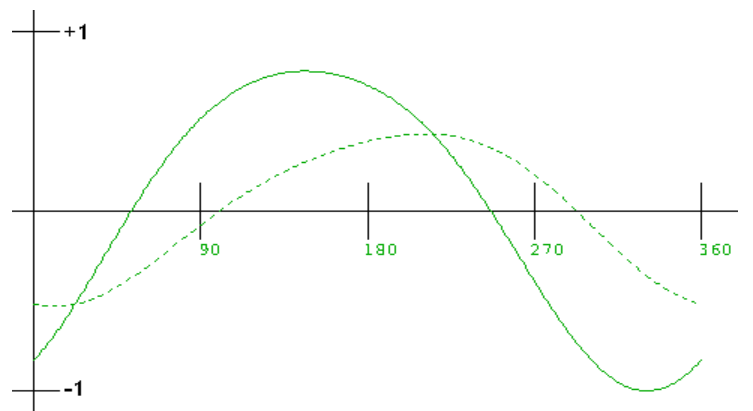

Figure 4: Normalized Shaking Forces for V-Twin Engine $\left(R_{X} / \Omega^{2}\right.$ - solid line, $R_{Y} / \Omega^{2}$ - broken line) Plotted Versus Crank Angle, $\theta$

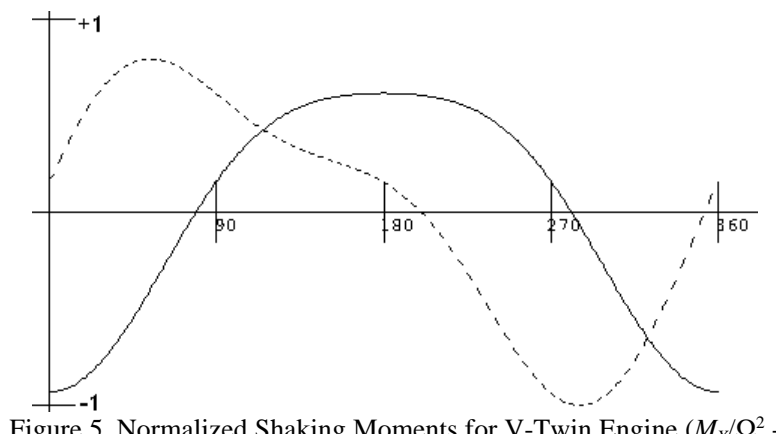

Figure 5. Normalized Shaking Moments for V-Twin Engine $\left(M_{X} / \Omega^{2}\right.$ solid line, $M_{Y} / \Omega^{2}$ - broken line) Plotted Versus Crank Angle, $\theta$. 
TABLE 3.

V-TWIN RESULTS

\begin{tabular}{cc}
\hline \hline $\operatorname{Max}\left|\frac{R_{X}}{\Omega^{2}}\right|$ & $519.3 *$ \\
\hline $\operatorname{Max}\left|\frac{R_{Y}}{\Omega^{2}}\right|$ & 275.4 \\
\hline $\operatorname{Max}\left|\frac{M_{O X}}{\Omega^{2}}\right|$ & 2.344 \\
\hline Max $\left|\frac{M_{O Y}}{\Omega^{2}}\right|$ & $2.517 *$ \\
\hline \hline Normalizing Value for Plots
\end{tabular}

On each plot, both curves are plotted to the same scale for comparison, and the curve with the larger excursion is normalized to 1.0. A Fourier analysis of these functions gives the following coefficients for the leading terms:

TABLE 4

CASE $1: R_{X} / \Omega^{2}$

\begin{tabular}{ccl}
\hline \multicolumn{3}{c}{ CASE $1: R_{X} / \Omega^{2}$} \\
\hline$n$ & $a_{n}$ & \multicolumn{1}{c}{$b_{n}$} \\
\hline 0 & $4 \cdot 10^{-14}$ & - \\
1 & $\mathbf{- 3 9 7 . 4 5 0 6}$ & $\mathbf{+ 2 3 5 . 1 4 2 0}$ \\
2 & $\mathbf{- 3 3 . 3 9 0 5}$ & $\mathbf{+ 4 7 . 2 2 1 3}$ \\
3 & +0.0000 & +0.0000 \\
4 & +0.1463 & +0.0000 \\
5 & +0.0000 & +0.0000 \\
6 & +0.0042 & +0.0000 \\
7 & +0.0000 & +0.0000 \\
8 & +0.0001 & +0.0000 \\
\hline \hline
\end{tabular}

TABLE 5 .

CASE $1: R_{Y} / \Omega^{2}$

\begin{tabular}{ccc}
\hline \hline$n$ & $a_{n}$ & \multicolumn{1}{c}{$b_{n}$} \\
\hline 0 & $6 \cdot 10^{-14}$ & - \\
1 & $\mathbf{- 2 3 5 . 1 4 2 0}$ & $\mathbf{+ 7 2 . 8 3 3 4}$ \\
2 & $\mathbf{- 3 3 . 3 9 0 5}$ & +0.0000 \\
3 & +0.0000 & +0.0000 \\
4 & +0.3533 & +0.0000 \\
5 & +0.0000 & +0.0000 \\
6 & +0.0042 & +0.0000 \\
7 & +0.0000 & +0.0000 \\
8 & +0.0001 & +0.0000 \\
\hline \hline
\end{tabular}

TABLE 6.

CASE $1: M_{o X} / \Omega^{2}$

\begin{tabular}{ccc}
\hline \hline$n$ & $a_{n}$ & \multicolumn{1}{c}{$b_{n}$} \\
\hline 0 & $4 \cdot 10^{-16}$ & - \\
1 & $\mathbf{- 1 . 9 4 7 7}$ & +0.0000 \\
2 & -0.4007 & +0.0000 \\
3 & +0.0000 & +0.0000 \\
4 & +0.0042 & +0.0000 \\
5 & +0.0000 & +0.0000 \\
6 & -0.0001 & +0.0000 \\
7 & +0.0000 & +0.0000 \\
8 & +0.0001 & +0.0000 \\
\hline \hline
\end{tabular}

TABLE 7. CASE 1: $M_{o Y} / \Omega^{2}$

\begin{tabular}{ccc}
\hline \hline$n$ & $a_{n}$ & \multicolumn{1}{c}{$b_{n}$} \\
\hline 0 & $5 \cdot 10^{-16}$ & - \\
1 & +0.0000 & $\mathbf{+ 1 . 9 4 7 7}$ \\
2 & $\mathbf{- 0 . 4 0 0 7}$ & $\mathbf{0 . 5 6 6 7}$ \\
3 & +0.0000 & +0.0000 \\
4 & +0.0102 & +0.0000 \\
5 & +0.0000 & +0.0000 \\
6 & -0.0001 & +0.0000 \\
7 & +0.0000 & +0.0000 \\
8 & +0.0000 & +0.0000 \\
\hline \hline
\end{tabular}

The values of order $10^{-14}$ and less are simply the roundoff error on zero values.

\section{Case 2 V6 with $60^{\circ}$ between Banks}

The parameters for this case are listed in Table 8 below. The two cylinder banks are each 30 off the vertical.

TABLE 8.

V6 ENGINEPARAMETERS

\begin{tabular}{cccc}
\hline \hline Cyl Number $j$ & $B_{j}(\mathrm{deg})$ & $C_{j}(\mathrm{deg})$ & $Z_{j}(\mathrm{~m})$ \\
\hline 1 & +30 & 0 & -0.850 \\
2 & -30 & 0 & -0.850 \\
3 & +30 & +120 & +0.000 \\
4 & -30 & +120 & +0.000 \\
5 & +30 & -120 & +0.850 \\
6 & -30 & -120 & +0.850 \\
\hline \hline
\end{tabular}

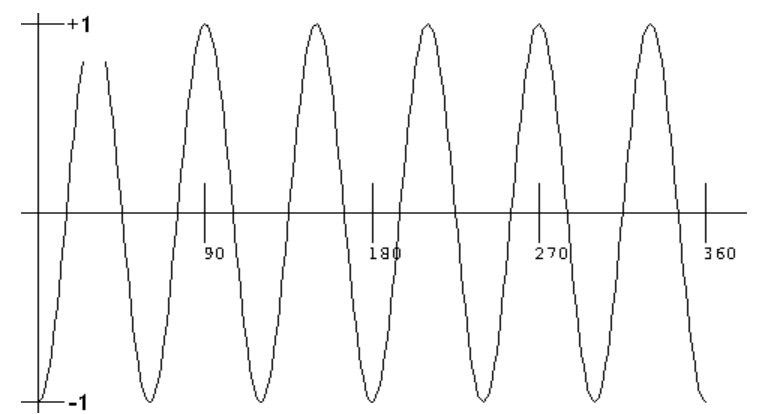

Figure 6. Normalized Shaking Forces for V6 Engine $\left(R_{X} / \Omega^{2}\right.$ - solid line, $R_{Y} / \Omega^{2}$ - broken line) Plotted Versus Crank Angle.

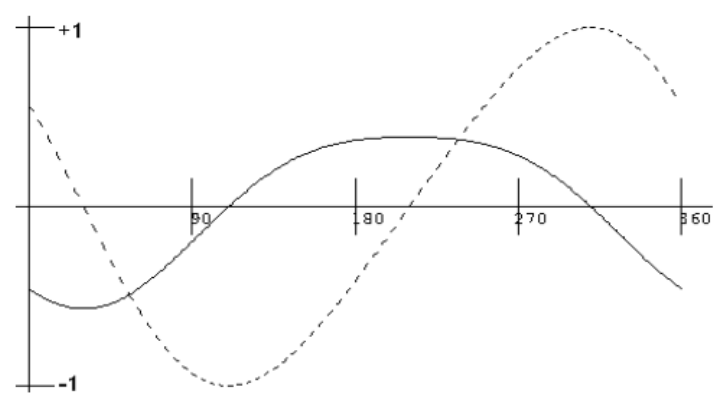

Figure 7. Normalized Shaking Moments for V6 Engine $\left(R_{X} / \Omega^{2}\right.$ - solid line, $R_{Y} / \Omega^{2}$ - broken line) Plotted Versus Crank Angle. 
TABLE 9.

V6 ENGINE RESULTS

\begin{tabular}{cc}
\hline Max $\left|\frac{R_{X}}{\Omega^{2}}\right|$ & $0.0309 *$ \\
\hline $\operatorname{Max}\left|\frac{R_{Y}}{\Omega^{2}}\right|$ & $2 \cdot 10^{-13}$ \\
\hline $\operatorname{Max}\left|\frac{M_{O X}}{\Omega^{2}}\right|$ & 381.5 \\
\hline Max $\left|\frac{M_{O Y}}{\Omega^{2}}\right|$ & $669.5^{*}$
\end{tabular}

When these functions are subject to Fourier analysis, the leading terms in the results are:

TABLE 10 CASE $2: R_{X} / \Omega^{2}$

\begin{tabular}{ccc}
\multicolumn{3}{c}{ CASE 2: $R_{X} / \Omega^{2}$} \\
\hline \hline$n$ & $a_{n}$ & \multicolumn{1}{c}{$b_{n}$} \\
\hline 0 & $7 \cdot 10^{-15}$ & - \\
1 & +0.0000 & +0.0000 \\
2 & +0.0000 & +0.0000 \\
3 & +0.0000 & +0.0000 \\
4 & +0.0000 & +0.0000 \\
5 & +0.0000 & +0.0000 \\
6 & $+\mathbf{0 . 0 3 0 9}$ & +0.0000 \\
7 & +0.0000 & +0.0000 \\
8 & +0.0001 & +0.0000 \\
\hline \hline
\end{tabular}

TABLE 11 . CASE $2: R_{Y} / \Omega^{2}$

\begin{tabular}{ccc}
\hline \hline$n$ & $a_{n}$ & \multicolumn{1}{c}{$b_{n}$} \\
\hline 0 & $4 \cdot 10^{-15}$ & - \\
1 & +0.0000 & +0.0000 \\
2 & +0.0000 & +0.0000 \\
3 & +0.0000 & +0.0000 \\
4 & +0.0000 & +0.0000 \\
5 & +0.0000 & +0.0000 \\
6 & +0.0000 & +0.0000 \\
7 & +0.0000 & +0.0000 \\
8 & +0.0000 & +0.0000 \\
\hline \hline
\end{tabular}

TABLE 12

CASE 2: $M_{o X} / \Omega^{2}$

\begin{tabular}{ccc}
\multicolumn{3}{c}{ CASE $2: M_{o X} / \Omega^{2}$} \\
\hline \hline$n$ & $a_{n}$ & $b_{n}$ \\
\hline 0 & $4 \cdot 10^{-14}$ & - \\
1 & $-\mathbf{2 7 7 . 6 5 8 7}$ & $\mathbf{- 1 6 0 . 3 0 6 3}$ \\
2 & $\mathbf{- 3 0 . 1 0 3 6}$ & $\mathbf{- 5 2 . 1 4 1 0}$ \\
3 & +0.0000 & +0.0000 \\
4 & +0.3185 & -0.5517 \\
5 & +0.0000 & +0.0000 \\
6 & +0.0000 & +0.0000 \\
7 & +0.0000 & +0.0000 \\
8 & +0.0000 & +0.0001 \\
\hline \hline
\end{tabular}

TABLE 13 .

CASE 2: $M_{o Y} / \Omega^{2}$

\begin{tabular}{ccc}
\hline \hline$n$ & $a_{n}$ & $b_{n}$ \\
\hline 0 & $4 \cdot 10^{-14}$ & - \\
1 & $\mathbf{+ 3 2 9 . 2 7 4 9}$ & $\mathbf{- 5 7 0 . 3 2 0 9}$ \\
2 & $\mathbf{+ 5 2 . 1 4 1 0}$ & $\mathbf{- 3 0 . 1 0 3 6}$ \\
3 & +0.0000 & +0.0000 \\
4 & -0.5517 & -0.3185 \\
5 & +0.0000 & +0.0000 \\
6 & +0.0000 & +0.0000 \\
7 & +0.0000 & +0.0000 \\
8 & +0.0001 & +0.0001 \\
\hline \hline
\end{tabular}

The major contributions are shown in boldface. As noted previously, the very small values for $a_{o}$ are actually simply round-off errors in what should be an exactly zero value

\section{CONCLUSION}

A rather simple approach has been demonstrated for the determination of shaking forces and shaking moment in slider crank machines such as IC engines. The method is based on the direct application of very fundamental principles of dynamics, and avoids many of the difficulties associated with the Newton's Law approach. While not well suited for hand calculation, the method is easily programmed for digital computer implementation. Initially, it provides the time dependent form for the shaking forces and moments, but these wave- forms are easily subject to Fourier analysis in the same computer program to obtain the components associated with each rotational order.

\section{REFERENCES}

[1] H. L. Guntur and K. Yulia, "Modelling and Analysis of the Dynamic Behavior of a Double Cylinder Inline 650cc Gasoline Engine with Crank Angle 0o for Rubber Mount," IPTEK Journal of Proceedings Series, vol. 1, no. 1, pp. 272-278, 2014.

[2] A. Zubaydi, N. Ariana, L. Baliwangi, A. A. Masroeri, F. Louhenapessy, M. Tukan and S. M. Taribuka, "Analysis of Dynamic Inertia Forces at Main Bearing of Ship Reciprocating Engines," IPTEK The Journal of Technology and Science, vol. 21, no. 4, pp. 215-222, 2010.

[3] S. Doughty, "Considerations in the Internal Force Analysis of Slider-Crank Machines," in ASME 2005 Internal Combustion Engine Division Fall Technical Conference (ICEF2005), Ottawa, 2005.

[4] S. Doughty, "Computer Determination of Shaking Forces in Articulated IC Engines," in SAE International Off-Highway \& Powerplant Congress \& Exposition, Milwaukee, 1988.

[5] S. H. Crandall, D. C. Karnopp, E. F. Kurtz and D. C. PridmoreBrown, Dynamics of Mechanical and Electromechanical Systems, New York: McGraw-Hill, 1968

[6] S. Doughty, Mechanics of Machines, New York: Wiley, 1988.

[7] B. Paul, Kinematics and Dynamics of Planar Machinery, New Jersey: Prentice-Hall, 1979.

[8] C. C. Pounder, Marine Diesel Engines 2nd Edition, London: Newnes, 1960. 


\section{APPENDIX - CYLINDER KINEMATICS}

For any connecting rod with zero cylinder center line offset, the following kinematic relations are valid:

$$
\begin{aligned}
& \phi(\theta)=\arcsin \left(\frac{R}{L} \sin \theta\right) \\
& x(\theta)=R \cos \theta+L \cos [\phi(\theta)]
\end{aligned}
$$

Differentiating with respect to $\theta$ gives

$$
\begin{aligned}
K_{\phi}(\theta) & =\frac{R \cos \theta}{L \cos [\phi(\theta)]} \\
K_{x}(\theta) & =-x(\theta) \cdot \tan [\phi(\theta)]
\end{aligned}
$$

and differentiating second time with respect to $\theta$ gives

$$
\begin{aligned}
L_{\phi}(\theta)= & -\frac{R \sin \theta}{L \cos [\phi(\theta)]}+K_{\phi}^{2}(\theta) \tan [\phi(\theta)] \\
L_{x}(\theta)= & -R \cos \theta-K_{\phi}^{2}(\theta) L \cos [\phi(\theta)] \\
& -L_{\phi}(\theta) L \sin [\phi(\theta)]
\end{aligned}
$$

Note in passing that these functions are very easily evaluated in computer code if evaluated numerically in the sequence presented here, without substituting one formula into the next. Full symbolic substitution, which is easily accomplished by a computer algebra program such as Maple ${ }^{T M}$ or Mathematica ${ }^{T M}$, results in very long, complicated expressions that defy interpretation and are difficult to program correctly.

For the center of mass motions, the ideas above are extended as follows:

$$
\begin{aligned}
& x_{1 c}(\theta)=u_{1 c} \cos \theta-v_{1 c} \sin \theta \\
& y_{1 c}(\theta)=u_{1 c} \sin \theta+v_{1 c} \cos \theta \\
& K_{x 1 c}(\theta)=-u_{1 c} \sin \theta-v_{1 c} \cos \theta \\
& K_{y 1 c}(\theta)=u_{1 c} \cos \theta-v_{1 c} \sin \theta \\
& L_{x 1 c}(\theta)=-u_{1 c} \cos \theta+v_{1 c} \sin \theta \\
& L_{y 1 c}(\theta)=-u_{1 c} \sin \theta-v_{1 c} \cos \theta
\end{aligned}
$$

$$
\begin{aligned}
& -u_{c} L_{\phi}(\theta) \cos [\phi(\theta)] \\
& -v_{c} L_{\phi}(\theta) \sin [\phi(\theta)]
\end{aligned}
$$

This completes all of the kinematic analysis required for the slider-crank mechanism analysis

(1)

